\title{
A DINÂMICA DA AGRICULTURA FAMILIAR A PARTIR DA TEORIA DE KARL POLANYI
}

\author{
Fabiola Graciele Besen ${ }^{1}$ \\ Clério Plein ${ }^{2}$
}

\begin{abstract}
Resumo: O artigo estuda a contribuição do pensamento de Karl Polanyi no debate sobre desenvolvimento rural e busca resgatar seus conceitos para entender a dinâmica da agricultura familiar no espaço rural. A mercantilização, classificada como a forma de integração predominante na economia, se faz presente em todas as instâncias da vida, mas outras formas de integração citadas por Polanyi, ainda permanecem no meio rural, e segundo Schneider e Escher (2011), essas outras formas de ordenamento e interação social e econômica poderiam representar a base a partir da qual se poderia constituir uma "outra" forma de desenvolvimento rural. Nesse sentido, o objetivo do artigo é entender, a partir da teoria de Karl Polanyi, como a agricultura familiar se organiza e se reproduz no meio rural.
\end{abstract}

Palavras Chave: Desenvolvimento, agricultura familiar, Karl Polanyi.

\section{THE DYNAMICS OF FAMILY AGRICULTURE FROM THE THEORY OF KARL POLANYI}

\begin{abstract}
The article studies the contribution of Karl Polanyi 's thinking in the debate on rural development and seeks to rescue his concepts to understand the dynamics of family agriculture in rural space. Mercantilization, classified as the predominant form of integration in the economy, is present in all instances of life, but other forms of integration cited by Polanyi still remain in the rural environment, and according to Schneider and Escher (2011), these other forms and social and economic interaction could form the basis for building a "different" form of rural development. In this sense, the aim of the article is to understand, from Karl Polanyi's theory, how family agriculture is organized and reproduced in the rural.
\end{abstract}

Key Words: Development, family farming, Karl Polanyi.

\section{LA DINÁMICA DE LA AGRICULTURA FAMILIAR A PARTIR DE LA TEORÍA DE KARL POLANYI}

Resumen: El artículo estudia la contribución del pensamiento de Karl Polanyi en el debate sobre desarrollo rural y busca rescatar sus conceptos para entender la dinámica de la agricultura familiar en el espacio rural. La mercantilización, clasificada como la forma de integración predominante en la economía, se hace presente en todas las instancias de la vida, pero otras formas de integración citadas por Polanyi, todavía permanecen en el medio rural, y según Schneider y Escher (2011), esas otras formas de ordenamiento e interacción social y económica podrían representar la base a partir de la cual se podría constituir una "otra" forma de desarrollo rural. En este sentido, el objetivo del artículo es entender, a partir de la teoría de Karl Polanyi, cómo la agricultura familiar se organiza y se reproduce en el medio rural.

Palabras Clave: Desarrollo, agricultura familiar, Karl Polanyi.

\section{Introdução}

A noção de desenvolvimento, vem ao longo do tempo, sofrendo alterações em seu significado, e por um longo período, em função das pautas sociopolíticas econômicas, no contexto pós $2^{\circ}$ Guerra Mundial, restringiu-se como uma expansão capitalista das formas de produção, voltados ao progresso técnico e de acumulação de riquezas, tendo no PIB seu principal indicador (BREINTENBACH et al, 2009; RODRIGUES e SANTOS,2017).

\footnotetext{
${ }^{1}$ Professora Assistente do Curso de Ciências Contábeis - Universidade Estadual do Oeste do Paraná - UNIOESTE, campus de Foz do Iguaçu. Bacharel em Ciências Contábeis - Mestre em Desenvolvimento Rural Sustentável UNIOESTE campus de Marechal Cândido Rondon.

2 Professor Adjunto na Universidade Estadual do Oeste do Paraná - Campus Francisco Beltrão. Graduado em Economia Doméstica pela Universidade Estadual do Oeste do Paraná - Unioeste, 2000. Mestre em Desenvolvimento Rural pela Universidade Federal do Rio Grande do Sul - UFRGS, 2003. Doutor em Desenvolvimento Rural pela Universidade Federal do Rio Grande do Sul - UFRGS em 2012.
} 
Na década de 50, o termo já era empregado correntemente na literatura econômica, tanto no discurso (neo)liberal, quanto no socialista (socialismo real existente), revigorado por teorias e princípios econômicos que vêm no Estado um dos impulsionadores da modernização, garantindo um importante papel ao desenvolvimento econômico e técnico (ALMEIDA, 2015).

Mas essa concepção de desenvolvimento, baseada na industrialização, urbanização e burocratização gerou efeitos sociais desastrosos: deterioração ambiental, êxodo rural, concentração urbana (BREINTENBACH et al, 2009). A partir dos anos 70 frente ao reconhecimento de que o modelo de desenvolvimento ocidental para diminuir a pobreza havia falhado, ganha espaço a ideia de desenvolvimento a longo prazo e com a abordagem de sensibilização em relação aos recursos não renováveis, portanto com uma visão a longo prazo (DOPFER, 1994 apud PLEIN, 2016).

As "crises" ambiental, econômica e social colocam em xeque esta noção generalizadora do progresso. Essas crises e a evolução social das sociedades "modernas" no século 20 esgotaram a força mobilizadora desta ideia (ALMEIDA, 2015, p. 35).

Nos anos 80, inicia-se um novo período de integração econômica, que abriu um novo cenário de desenvolvimento inspirado no fundamentalismo de mercado e com base no fracasso de políticas implementadas em países em desenvolvimento (PLEIN, 2016). Entretanto, nesse período, retomam-se algumas teorias baseadas no desenvolvimento "endógeno", que consideram o desenvolvimento como um processo territorial e não funcional, baseadas em estudos de caso, com políticas concebidas e implementadas por atores locais, provocando uma mudança nos modelos e nas políticas de desenvolvimento (PLEIN, 2016).

A partir da década de 90 as questões, econômicas, políticas, sociais e ambientais começam a fazer parte das discussões sobre desenvolvimento, além das questões sobre crescimento econômico e distribuição de riquezas, sustentabilidade e justiça social (SCHNEIDER, 2016).

Assim, a inclusão e importância de outras variáveis a serem consideradas nas discussões sobre o desenvolvimento, como as questões culturais, sociais e ambientais, passam a ser defendidas e problematizadas pela literatura (BREITENBACH et al, 2009).

Segundo Almeida (2015), no campo da agricultura, a noção de desenvolvimento encontrou, no decorrer das décadas de 1950 e 1960, nos Estados Unidos e na Europa, um terreno de aplicação bem fértil.

Sob a ação conjugada do Estado, das indústrias agroalimentares e de uma camada de agricultores "empresariais", o "setor" agrícola se insere cada vez mais no sistema econômico; leis são impostas nesses países visando transformar a agricultura, "setor" ideologicamente considerado "arcaico", tradicional, em 
atraso, setor "moderno", participando do crescimento econômico nacional (ALMEIDA, 2015, p. 38). ${ }^{3}$

Durante esse período, a agricultura sofreu não apenas, uma mudança de ordem quantitativa, mas uma transformação radical de seus fatores de produção, comercialização, bem como suas estruturas sociais. "Os planos de desenvolvimento inspirados nessa visão desenvolvimentista passam a definir as competências dos agricultores e as características do sistema técnico que eles devem colocar em operação" (ALMEIDA, 2015, p. 40). Do ponto de vista metodológico, essa visão de desenvolvimento, julgaria mais ou menos desenvolvida a produção agrícola que fosse mais ou menos tecnificada (ALMEIDA, 2015).

Todo esse padrão tecnológico produtivo resultou em desigualdade social e problemas relativos à sustentabilidade (econômica e ecológica) da produção agrícola. Surge então, uma visão, a partir dos anos 80, de uma estratégia de desenvolvimento agrícola sustentável, que tem como filosofia neutralizar ou minimizar os efeitos antrópicos no meio ambiente (ALMEIDA, 2015).

Nesse cenário de mercantilização e crescente padrão tecnológico, ainda persiste a figura do agricultor familiar. O agricultor familiar, segundo Wanderley (2001), não é uma figura nova na sociedade, mas segundo a autora (2001, p.47-48), os agricultores familiares "são portadores de uma tradição (cujos fundamentos são dados pela centralidade da família, pelas formas de produzir e pelo modo de vida), mas devem adaptar-se às condições modernas de produzir e viver em sociedade", uma vez que os mercados estão em constante mudança e o Estado e as políticas também se alteram.

Conforme Schneider (2016), a agricultura familiar, além de produzir e fornecer alimentos básicos de preço acessível e de boa qualidade para a população, ainda se reproduz como segmento social diferenciado no mundo capitalista.

Corroborando com o tema, Ploeg (2008) aponta que:

A agricultura familiar relaciona-se de forma diferente com os recursos e a natureza. Tanto os recursos naturais, quanto os sociais, são configurados e reconfigurados, gerando um processo de coprodução. Através da coprodução, os recursos são convertidos em uma variedade de bens e serviços e ao mesmo tempo reproduzidos como recursos. A relação com o mercado não é de dependência, pois os agricultores podem adquirir seus recursos através de

\footnotetext{
${ }^{3}$ O Brasil, no início da década de 1960, passou por uma crise política e econômica. Essa crise deu-se, pois desde a década de 1930, em que houve a grande Depressão e depois com o governo de Juscelino Kubistchek, na segunda metade da década de 1950, o Brasil adotou como principal objetivo a industrialização, para aproximar-se das economias capitalistas industrializadas. Consolidou-se como o objetivo primordial da política econômica do governo na época. Conforme Grisa e Schneider (2015), nesta estratégia nacional de desenvolvimento, O Estado desempenhou vários papéis: foi agente produtivo criando infraestruturas estatais, agente financeiro, transformando a estrutura industrial, articulador de capitais privados nacionais e internacionais e formulou e executou políticas públicas privilegiando a economia industrial.
} 
transações com os mercados, mas também podem ser reproduzidos na própria unidade agrícola. Os mercados geralmente são locais, redes curtas de comercialização. Em relação a produção, geralmente há uma pluriatividade, várias atividades que permitem aumentar sua renda e diminuir a dependência dos mercados (PLOEG, 2008, p.8).

Diante do considerado em tela, o objetivo do presente artigo é apresentar, a partir da teoria de Karl Polanyi, como a agricultura familiar se organiza e se reproduz no meio rural.

O artigo está estruturado em cinco seções, além dessa introdução. Na segunda seção, fazse uma apresentação do quadro teórico de Karl Polanyi, conceitos sobre desenvolvimento rural e agricultura familiar. Na terceira seção, apresenta-se a metodologia empregada para a construção do estudo. A quarta seção traz uma discussão sobre a agricultura familiar, compreendendo-a como uma forma de ordenamento e interação social e econômica que poderia representar a base a partir da qual se pensaria em uma "outra" forma de desenvolvimento rural. Na seção cinco, as considerações finais, seguido das referências.

\section{Referencial Teórico}

Esse tópico traz uma contextualização sobre o desenvolvimento rural, agricultura familiar e os conceitos presentes na obra de Karl Polanyi, e servirão para retirar inferências e iniciar um diálogo a fim de alcançar o objetivo do artigo.

\section{Elementos Conceituais da Obra de Karl Polanyi}

O húngaro Karl Polanyi (1886-1964), foi um cientista social, com um campo de investigação multidisciplinar, se preocupou em compreender a economia plural e o processo de desenvolvimento em termos multidimensionais (RODRIGUES e SANTOS, 2017).

Polanyi, em sua obra mais conhecida, A Grande Transformação: as origens políticas $e$ econômicas do nosso tempo, publicada pela primeira vez em 1944, na fase final da II Grande Guerra, como consequência da Revolução Industrial e das políticas liberais do capitalismo, fala de problemas que assolam o mundo na atualidade: a pobreza, a exclusão social, as falhas do capitalismo e do sistema financeiro, os problemas ecológicos, e por essa razão, seus estudos vem sendo retomados (PEREIRA, 2016).

Conforme Polanyi (2012), os esforços para identificar o problema geral da subsistência do homem, provém de um pensamento criado e arraigado, peculiar às condições de vida no tipo de economia que o século XIX criou nas sociedades industrializadas. Houve uma separação do mercado das demais instituições sociais, tornando-o autônomo, e o mercado, que antes estava imerso na sociedade, que o regulava, passou a ser o regulador da sociedade. 
A base conceitual e metodológica da abordagem de Polanyi consiste na distinção que o autor faz entre economia formal e substantiva (LISBOA, 2000). Conforme Polanyi, o termo econômico tem duas origens, de acordo com a percepção da teoria neoclássica, com Carl Menger, em sua obra "Princípios de Economia", de 1871.Para Menger, a economia tinha duas vertentes: uma era a economizadora, proveniente da insuficiência dos meios e a outra, chamada de tecnoeconomica, era decorrente dos requisitos físicos da produção, independente da suficiência ou insuficiência deles.

O primeiro significado, formal, "vem da relação meios-fios", e se refere à escolha racional dos recursos escassos em busca da maximização do lucro. "Busca obter o máximo a partir dos recursos de que se dispõe" (POLANYI, 2012, p. 64). O segundo significado, o substantivo, "provém da flagrante dependência do homem em relação à natureza e aos seus semelhantes para sobreviver" e se refere a interação do meio social e natural, através do qual os seres humanos conseguem satisfazer suas necessidades materiais, através dos meios disponíveis (POLANYI,2012, p.64). ${ }^{4}$

Para Polanyi (2012), a economia é um processo dinâmico e histórico, [...]um processo instituído de interações que servem para satisfazer as necessidades materiais[...] (Polanyi, 2012, p.78), e não uma série de situações de equilíbrios agrupados por meio de "estática comparativa". Segundo a teoria econômica ortodoxa, a economia se resume a alocação eficiente de recursos escassos objetivando a maximização da utilidade individual (SCHNEIDER e ESCHER, 2011).

Assim, compreender os dois significados de economia é o ponto de partida para desfazer a falácia economicista, de que os motivos econômicos movem o ser humano. "O Homem não é um ser econômico, mas um ser social” (POLANYI, 2012, p.215), já que os mesmos são capazes de trabalhar por uma grande variedade de motivações (políticas, religiosas, estéticas), e que sua economia se encontra, como regra, submersa, em suas relações sociais (POLANYI, 2012).

Nesse sentido, já que a economia está incrustada (ideia de embeddedness ${ }^{5}$ ) na sociedade, é preciso entender os aspectos políticos e culturais nas relações dos processos econômicos. O processo econômico, para Polanyi (2012), se dá em dois níveis: o da atividade interativa entre os seres humanos e seu entorno; e o da institucionalização deste processo.

\footnotetext{
${ }^{4}$ O que acontece, segundo Polanyi (1976, 1977b), é que a economia convencional funde a noção de subsistência com a de escassez, incorrendo num equívoco metodológico. Pois, tal fusão só é possível em um caso específico e aistórico - o sistema teórico de "oferta-demanda-preços-equilíbrio". Mas, como a atividade econômica não se reduz ao caso formal da teoria neoclássica, apenas o significado substantivo da economia pode proporcionar às ciências sociais os conceitos adequados ao estudo de "todas as economias que existiram e existem", na medida em que se fundamenta nos fatos sociais e naturais empíricos, concretos, e não em abstrações, lógicas, mas destituídas de fundamento e de conteúdo histórico (SCHNEIDER e ESCHER, 2011, p.190)

${ }^{5} \mathrm{O}$ conceito expressa a ideia de que as estruturas sociais, estabelecidas e enraizadas em regras, normas, convenções, hábitos, etc. condicionam o comportamento social dos indivíduos. (SCHNEIDER e ESCHER, 2011).
} 
Segundo Polanyi, os movimentos situacionais implicam em deslocamento espacial (transporte) ou em transformação dos elementos materiais (produção). De acordo com a utilidade que tem para o consumidor, os produtos são classificados como: de ordem superior (bens de consumo), na medida em que satisfazem as necessidades de consumo direto; ou de ordem inferior (bens de produção), na medida em que satisfazem as necessidades de consumo indireto, intermediário, combinando-se com outros elementos no processo produtivo. Os movimentos apropriacionais, por sua vez, implicam nas relações entre os seres humanos na aquisição, administração e dotação dos bens de produção e de consumo, através de transações, tributações, direitos legais, convenções, etc.; e dependem das formas como a força de trabalho, o conhecimento e a tecnologia são postos em movimento no processo de produção e de como o produto dessa atividade é distribuído entre os membros da sociedade. (POLANYI, 2012, p.293-294).

Os sistemas econômicos nas sociedades pré-capitalistas, chamados por Polanyi (2012) de “formas de integração" eram organizados segundo três princípios: reciprocidade, redistribuição e troca mercantil.

Reciprocidade e simetria: os bens e serviços são movimentados entre pontos correspondentes de um grupamento simétrico. Os recursos e o uso produtivo dos mesmos se dão por relações recíprocas: parentesco, amizade, cooperação.

Redistribuição e centralidade: há um centro, onde a produção do grupo é armazenada para ser repartida de forma igual a todos. O movimento dos bens se dá em direção ao centro e retorno aos consumidores, e esse movimento ocorre conforme o costume, a lei ou decisão central ad hoc. Para que o movimento ocorra de forma adequada, deve haver uma organização central, tanto em termos políticos, quanto econômicos.

Intercâmbio e mercado: os bens e serviços são movimentados para o ganho que cada uma das pessoas envolvidas deseja. Nessa forma de integração, os direitos e as apropriações organizações são determinadas pelos direitos de propriedade e pelas relações com os materiais derivados. A distribuição é feita através de compra e venda, fazendo uso do mecanismo de preços e do dinheiro, como expressão do poder de compra (SCHNEIDER e ESCHER, 2011).

Esses princípios eram organizadores de um sistema social que não tinha o lucro como motivação central, a economia era um meio de subsistência para satisfazer as necessidades humanas "O sistema econômico estava submerso em relações sociais gerais; os mercados eram apenas um aspecto acessório de uma estrutura institucional controlada e regulada, mais do que nunca, pela autoridade social" (Polanyi, 2000, p. 88).

Com o avanço do capitalismo, a economia de mercado passou a regular a sociedade, já que esse sistema é "um sistema autorregulável de mercados, em termos ligeiramente mais técnicos, é uma economia dirigida pelos preços do mercado e nada além dos preços do mercado. 
Um sistema, capaz de organizar a totalidade da vida econômica sem qualquer ajuda ou interferência externa" (POLANYI, 2000, p. 62).

A transformação da terra e do trabalho em mercadorias, promovido pelo sistema de mercado, foi o principal fator para o desmoronamento social, já que o uso da força passou a se chamar salário e o uso da terra passou a se chamar renda (POLANYI, 2012).

Ao dispor da força de trabalho de um homem, o sistema disporia também, incidentalmente, da entidade física, psicológica e moral do 'homem' ligado a essa etiqueta. Despojados da cobertura protetora das instituições culturais, os seres humanos sucumbiriam sob os efeitos do abandono social; morreriam vítimas de um agudo transtorno social, através do vício, da perversão, do crime e da fome. A natureza seria reduzida a seus elementos mínimos, conspurcadas as paisagens e os arredores, poluídos os rios, a segurança alimentar ameaçada e destruído o poder de produzir alimentos e matérias-primas (POLANYI, 2000, pg. 95)

Segundo Polanyi, “Os 'motivos econômicos' reinavam supremos, num mundo próprio, e o

indivíduo foi levado a neles calcar os seus atos, sob a pena de ser esmagado pelo mercado avassalador” (2012, p. 213).

Polanyi, (2012, p.40), busca em sua obra demonstrar que "a economia de mercado é uma estrutura institucional, e que nunca esteve presente a não ser em nosso tempo e, mesmo assim, ela estava apenas parcialmente presente", quer dizer, o mercado não deve ser o fio condutor da sociedade, embora a dinâmica do mercado seja importante para o desenvolvimento de um país, Estado ou município, mas ela deve fazer parte de uma estrutura social.

Segundo Abramovay (2004), Polanyi mostrou que esse sistema de mercado não contém o conjunto das atividades necessárias à reprodução social e à sobrevivência humana. A economia mercantil é o modo de produção dominante, mas não representa a totalidade das economias na atualidade. Para Polanyi, diferentes formas de integração podem coexistir, mesmo, em uma sociedade capitalista.

São os chamados "contramovimentos", e que podem acontecer a partir da capacidade dos atores em "(re)construir processos que promovam diversificação produtiva e tecnológica, economias de escopo, bem como mecanismos de troca e distribuição enraizados em relações sociais baseadas em princípios de reciprocidade e redistribuição" (Polanyi, 2000).

Por essa razão, há a necessidade de identificar as formas de integração citadas por Polanyi, que ainda estão presentes, sobretudo no meio rural, buscando outras abordagens e rumos para um novo desenvolvimento rural.

\section{Desenvolvimento Rural}


Segundo Ellis e Biggs (2001) o desenvolvimento rural teve ao longo dos últimos cinquenta anos períodos bem distintos. Nesse contexto, cabe destacar uma visão geral dos principais temas sobre desenvolvimento rural, dominantes e secundários que ocorreram ao longo dos últimos 50 anos, a partir da discussão de Frank Ellis e Stephen Biggs (2001).

O Quadro 1, de Ellis e Biggs (2001) demonstra de forma resumida os grandes impactos no desenvolvimento rural até os dias atuais.

QUADRO 1 - Cronograma de ideias de desenvolvimento rural 1950-2000

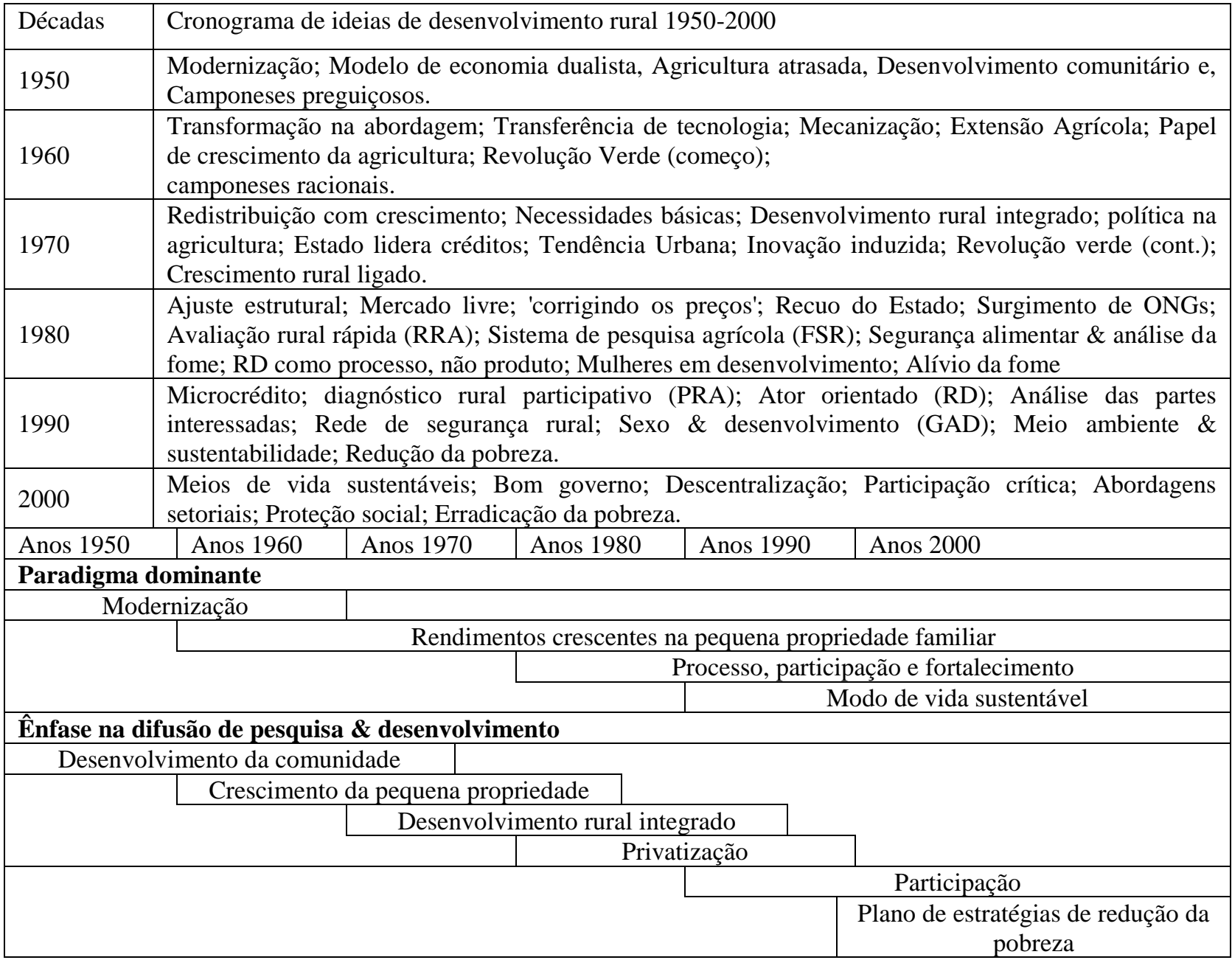

FONTE: Ellis, F. Biggs, S. (2001), adaptado pelos autores.

No início da década de 50, afirmam, Ellis e Biggs (2001), o desenvolvimento rural pautava-se na ideia que a maioria dos agricultores, chamados de 'subsistência' ou 'tradicionais' não acompanhariam o desenvolvimento econômico, nem seriam capazes de aumentar a produtividade. O papel deles que cabia a eles era secundário, quer dizer, seriam fornecedores de 
recursos para o setor moderno da economia. Este setor moderno constituído pelas grandes propriedades rurais e com uma agricultura em larga escala, poderiam fazer uso mais eficiente dos recursos e tecnologias modernas, e assim tomaria o lugar das pequenas propriedades rurais (ELLIS e BIGGS, 2001).

Nos anos 60, houve o início da Revolução Verde, com transferência de tecnologia, mecanização e extensão agrícola. O camponês passou a ser visto como um ser racional. Na década de 1970, o Estado entra na agricultura através de políticas agrícolas, com liberação de crédito visando principalmente a continuidade da Revolução Verde. Os anos 1980 veem a retirada do Estado das políticas de desenvolvimento, ocorrendo um ajustamento estrutural póscrise. Há um aumento das ONGs e o desenvolvimento rural passa a ser visto como um processo e não como um produto (ELLIS e BIGGS, 2001).

A década de 1990 é caracterizada pela entrada do microcrédito, discussões sobre gênero, participação dos atores no processo, e preocupação com o meio ambiente, sustentabilidade e redução da pobreza. A partir dos anos 2000, a preocupação com a erradicação da pobreza, boa governança, com os meios de subsistência sustentáveis são o destaque nas discussões no desenvolvimento rural (ELLIS e BIGGS, 2001).

O paradigma da modernização da agricultura, que dominou a teoria, as práticas e as políticas, como a melhor alternativa para aumentar a renda e o desenvolvimento das comunidades rurais, vem sendo substituído, por um novo paradigma, o do "desenvolvimento rural", que busca um novo modelo para o setor agrícola, através da sinergia com os ecossistemas locais, a valorização das economias de escopo em detrimento das economias de escala e a pluriatividade das famílias rurais (PLOEG, 2000).

\section{Agricultura Familiar}

O conceito de agricultura familiar ainda está em construção, mas é importante sua conceituação, principalmente para diferenciá-lo do conceito de campesinato, utilizado por alguns estudiosos do mundo rural. Abramovay (2012, p.142), afirma ser necessária essa diferenciação, pois "tanto a venda das safras como a compra dos insumos passam por uma integração parcial a mercados incompletos", no caso do campesinato, e por aí, se estabelece uma diferença de natureza social entre o campesinato e a agricultura familiar.

Sob o ângulo marxista, Lênin (1969), acreditava que o destino do camponês seria trágico: ele seria extinto pela dinâmica da diferenciação entre os produtores, pois como produtor de mercadorias, ele se desdobraria em uma das duas classes fundamentais da sociedade: o proletariado ou a burguesia. Kautsky (1980), acreditava que na ideia de industrialização da 
agricultura, e na impossibilidade de o pequeno agricultor não conseguir incorporar essas tecnologias, sendo incapaz de resistir a concorrência das grandes empresas agrícolas (ABRAMOVAY, 2012).

Marx (1818 - 1883), apesar da importância da agricultura em sua obra, não existe nada em seu trabalho que contemple o que se considera o eixo de articulação da questão agrária: a produção familiar na agricultura, suas tendências e suas funções no desenvolvimento capitalista. De modo geral, os clássicos marxistas em suas tratativas sobre a questão agrária, refletem muito mais as circunstâncias específicas de sua época do que uma teoria universal a respeito do desenvolvimento do capitalismo no campo (ABRAMOVAY, 2012).

Ainda, conforme Abramovay (2012, p.34), Alexander Chayanov (1888-1930), e posterior a ele o polonês Jerzy Tepich (1973), buscaram identificar algo que as teorias marxistas entendiam como um contrassenso: "uma definição de campesinato cuja base seria a própria família, e as determinações que a estrutura familiar impõe sobre o comportamento econômico".

Abramovay (2012) chama a atenção para a diferenciação entre campesinato e agricultura familiar. O agricultor familiar ao se integrar ao mercado econômico, perde seu caráter camponês, pois o camponês se insere de forma parcial aos mercados incompletos. Assim, a utilidade de uma definição precisa é necessária para entender o paradoxo de um sistema econômico que, ao mesmo tempo em que aniquila a produção camponesa, ergue a agricultura familiar como a principal base social de desenvolvimento.

No Brasil, no final da década de 80 e início da década de 90, o debate sobre agricultura familiar ganha força com a criação do Programa Nacional de Fortalecimento da Agricultura (PRONAF) em 1995, e passa a ser vista como categoria no meio rural, desencadeando a emergência de outras políticas diferenciadas de desenvolvimento rural; a criação do MDA em 1999 (Ministério do Desenvolvimento Agrário) e a criação da Secretaria da Agricultura Familiar (SAF) em 2001, que institucionalizou a dualidade da estrutura agrária e fundiária no País e a Lei da Agricultura Familiar que reconheceu a categoria social e conforme Grisa e Schneider (2015), a partir desses eventos a agricultura familiar passou a fazer parte da arena das políticas públicas buscando alcançar seus objetivos (GRISA e SCHNEIDER, 2015).

Wanderley (2001) afirma que o agricultor familiar não é uma figura nova na sociedade (produto do Estado ou de suas políticas), mas foi a partir da década de 90, com a mudança no cenário político, que esses atores passaram a ter mais representatividade e que surgiram várias definições para essa categoria social.

Além das definições normativas e operacionais (Lei de Agricultura Familiar, INCRA, FAO, Estatuto da Terra), que servem como base para a construção de políticas públicas, cabe 
destacar as definições que abrangem a agricultura familiar, não somente pelo tamanho do estabelecimento, como quando se fala da agricultura de pequena escala, mas também pela forma com que as pessoas cultivam e vivem.

Segundo Ploeg (2014) agricultura familiar é também considerada uma forma de vida.

O estabelecimento familiar faz parte da paisagem rural. Nele, pode-se trabalhar com a natureza, em vez de contra ela, ao se valer dos processos e dos equilíbrios ecológicos (em vez de interromper) e preservar a beleza e a integridade das paisagens. Quando a agricultura familiar trabalha com a natureza, contribui localmente para a conservação da biodiversidade e para a luta contra as mudanças climáticas globais. Seu trabalho implica uma interação contínua e direta com a natureza viva - uma característica altamente valorizada pelos próprios agricultores (PLOEG, 2014, p.10).

Abramovay (1997) define agricultura familiar, destacando alguns aspectos relevantes:

A agricultura familiar é aquela em que a gestão, a propriedade e a maior parte do trabalho vêm de indivíduos que mantêm entre si laços de sangue ou de parentesco. Que esta definição não seja unânime e muitas vezes tampouco operacional é perfeitamente compreensível, já que os diferentes setores sociais e suas representações constroem categorias científicas que servirão a certas finalidades práticas: a definição de agricultura familiar, para fins de crédito, pode não ser exatamente a mesma daquela estabelecida com finalidades de quantificação estatística num estudo acadêmico. O importante é que estes três atributos básicos (gestão, propriedade e trabalho familiares) estão presentes em todas elas (ABRAMOVAY, 1997, p. 03).

Assim, a maioria das definições de agricultura familiar citadas acima baseiam-se na mão de obra utilizada, no tamanho da propriedade, na direção dos trabalhos e na renda gerada pela atividade agrícola. Em todas há um ponto em comum: ao mesmo tempo em que é proprietária dos meios de produção, a família assume o trabalho no estabelecimento. Percebe-se, em todos esses conceitos que se toma como base a relação entre terra, trabalho e família e que é justamente a relação entre estes três fatores que diferenciam a agricultura familiar das outras formas de agricultura (TINOCO, 2006).

As previsões apocalípticas sobre o desaparecimento do campesinato não se confirmaram, embora tenha havido uma metamorfose e a agricultura familiar embora seja oriunda do campesinato, tem uma integração mais crescente aos mercados (ABRAMOVAY, 2012). Atualmente, conforme os dados da FAO: “a agricultura familiar é de longe a forma mais prevalente de agricultura no mundo. Estimativas sugerem que ela ocupa cerca de 70-80\% das terras agrícolas e produzem mais de $80 \%$ dos alimentos do mundo em termos de valor" (2014, p.11)

Um estudo desenvolvido pelo Programa das Nações Unidas para o Desenvolvimento (2011) "sugere que a agricultura familiar poderá ser decisiva para gerar resiliência ambiental e 
fortalecer os modos de vida rurais de tal forma que sejam mais sustentáveis e aptos a enfrentar as transformações ambientais geradas pelas mudanças climáticas” (SCHNEIDER, 2016, p.13).

\section{Procedimentos Metodológicos}

A abordagem metodológica desse artigo é uma discussão teórica sobre a teoria de Karl Polanyi, resgatando a contribuição desse autor para o entendimento da dinâmica da agricultura familiar e do desenvolvimento rural sustentável.

O método de abordagem utilizado foi o dedutivo, pois a pesquisa partiu de princípios considerados como verdadeiros, para chegar a conclusões de maneira puramente formal, em virtude unicamente de sua lógica (GIL, 1994).

A pesquisa se classifica como bibliográfica, quanto a tipologia, pois interpreta e discute um tema com fundamento em referências teóricas. O presente estudo é resultado de uma pesquisa qualitativa, em que os resultados não são vislumbrados de forma numérica ou estatística. A pesquisa qualitativa segundo Richardson (1999, p. 90) “pode ser caracterizada como a tentativa de uma compreensão detalhada dos significados e características situacionais apresentadas pelos entrevistados em lugar da produção de medidas quantitativas de características ou comportamentos.”

\section{Contribuições da concepção teórica de Karl Polanyi ao desenvolvimento rural}

A abordagem metodológica desse artigo é uma discussão teórica a partir da teoria de Karl Polanyi, resgatando a contribuição desse autor para inferir sobre os processos e questões inerentes ao desenvolvimento rural e como as diferentes formas de integração da economia se organizam e se reproduzem no meio rural, especialmente a agricultura familiar.

Segundo Polanyi (2012), o desenvolvimento é um processo que ultrapassa o domínio da economia, pois engloba um conjunto de aspectos que interagem entre si (sociais, culturais, políticos, econômicos e ambientais), trata-se desse modo, de um fenômeno multidimensional. Ele é instituído porque é definido pela interação, empiricamente construída, entre o homem e seu ambiente, resultando na satisfação tanto das suas necessidades materiais quanto das psicológicas (RODRIGUES e SANTOS, 2017)

A figura abaixo apresenta essa interação. Segundo Polanyi (2000, pg. 214), o "que chamamos de terra é um elemento da natureza inexplicavelmente entrelaçado com as instituições do homem", ou seja, terra e trabalho são originalmente inseparáveis, "o trabalho é parte da vida, a terra continua sendo parte da natureza, a vida e a natureza formam um todo articulado" (POLANYI, 2000, pg. 214). 
$\mathrm{O}$ autor alerta que se os três fossem somente regulados pelo mercado, simplesmente "resultaria no desmoronamento da sociedade" (POLANYI, 2000, p. 94).

Figura 01: Desenvolvimento sustentável na perspectiva de Karl Polanyi

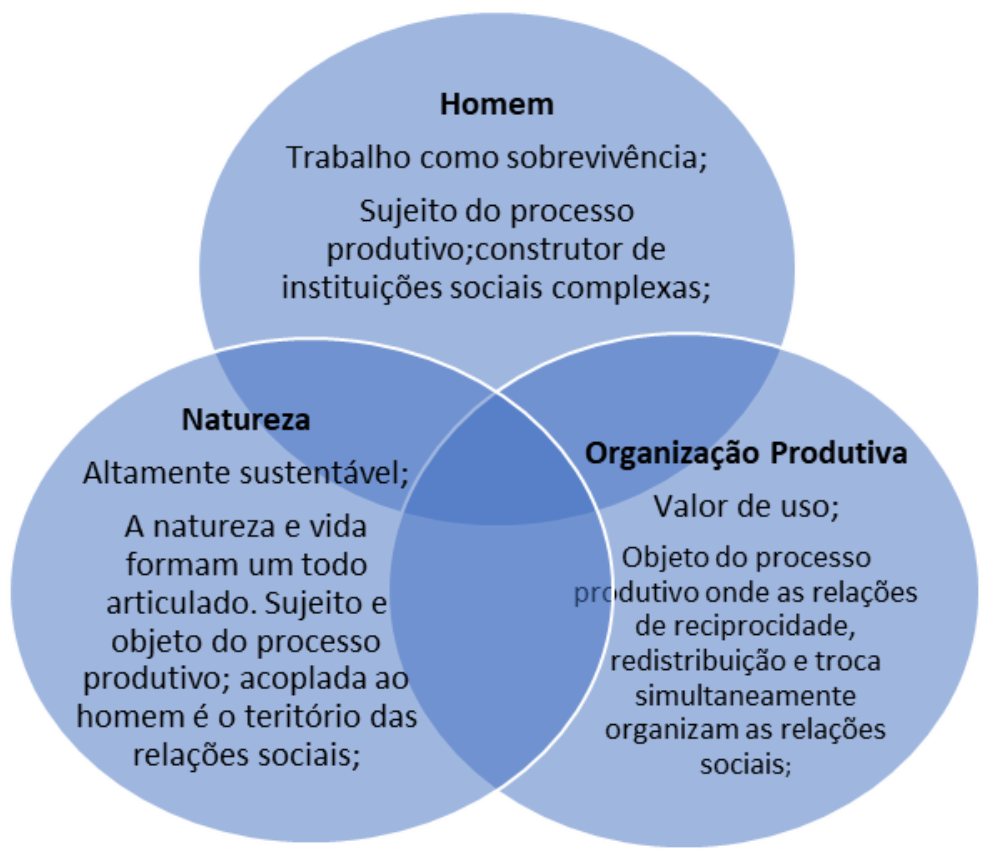

Fonte: Polanyi, (2012), adaptado pelos autores.

Ao realizar sua crítica a economia de mercado, Polanyi (2000;2012) afirma que a falácia economicista, desenraizada da sociedade, causou a separação daquilo que não se pode separar, ou seja, homem, natureza e organização produtiva. "A sociedade do século XIX organizou-se de um modo que fazia com que apenas a fome e o lucro fossem motivações eficazes para o indivíduo participar da vida econômica” (POLANYI, 2012, p.55). Para Polanyi (2012), o homem deve ter o trabalho como subsistência e não ser motivado pela fome ou desejo do lucro, a organização produtiva deve ter valor de uso e não ser considerada uma simples mercadoria, e a natureza precisa ser altamente sustentável.

O anseio da obra de Polanyi é mostrar a necessidade de reconstrução social através de outras forças que possam mover o sistema rumo ao equilíbrio (STIGLITZ, 2012).

Quais seriam essas outras forças ou os contramovimentos dentro do desenvolvimento rural? Atualmente, há discussões sobre desenvolvimento rural que tratam de perspectivas relacionadas a território, ruralidade, desenvolvimento local. Schneider (2009) aponta os eixos temáticos que vem sendo tratados por estudiosos do mundo rural, agências e organizações nacionais e internacionais: “(a) a ruralidade é heterogênea e não circunscrita às atividades agrícolas; (b) os territórios são espaços adequados para se pensar a articulação entre escalas 
regionais e locais e a globalização; (c) o desenvolvimento precisa levar em conta não apenas questões econômicas, tecnológicas e produtivas, mas também culturais e ambientais; (d) a mudança é um processo lento, que precisa trazer efeitos práticos como melhorar a renda e a qualidade

vida, mas também incidir sobre a mentalidade das pessoas envolvidas e ser capaz de ser assimilado pelas instituições” (SCHNEIDER et al 2009, p.207).

Embora, no meio rural, o capitalismo, chamado de "moinho satânico" por Polanyi tenha causado impactos, em função de um sistema de produção altamente tecnificada, que exclui as formas de produção diferenciadas, Polanyi aponta para os contramovimentos, que são as práticas diversas e heterogêneas que os agricultores familiares buscam para defender e criar autonomia e melhores condições de vida como respostas locais para problemas globais.

Polanyi explica que nenhuma sociedade não capitalista viveu um tipo de sistema econômico baseado no livre intercâmbio, totalmente regulado por mercados (RADOMSKY e SCHNEIDER, 2007, p. 258). Em um contexto geral, Polanyi não se volta contra os mercados ou o comércio, mas acredita que a sociedade não deve ser controlada pelo mercado, ou pela troca mercantil, a forma de integração predominante no capitalismo. Nesse sentido, as outras duas formas de integração citadas por Polanyi (2012), reciprocidade e redistribuição podem atuar dentro de uma sociedade capitalista.

"Estas "formas de integração" institucionalizam-se por meio da socialização de práticas baseadas em dispositivos de ação coletiva e em sistemas de regras, como parte reguladora do ordenamento da vida social, econômica e política das pessoas, com seus valores e lógicas de operação específicas (SCHNEIDER e ESCHER, 2011, p.193.)

No meio rural, embora não tenha ocorrido o fim do campesinato, conforme os autores clássicos marxistas previam, houve um ponto de ruptura e mudanças na forma de produção, ocorrendo uma transição do campesinato para a agricultura familiar. Wanderley (2009, p.189) afirma que se deve "considerar a capacidade de resistência e de adaptação dos agricultores aos novos contextos econômicos e sociais".

Mesmo integrada ao mercado e respondendo às suas exigências, o fato de permanecer familiar não é anódino, e tem como consequência o reconhecimento de que a lógica familiar, cuja origem está na tradição camponesa, não é abolida; ao contrário, ela permanece inspirando e orientando [...] as novas decisões que o agricultor deve tomar nos novos contextos a que está submetido [...] a família continua sendo o objetivo principal que define as estratégias de produção e de reprodução e a instância mediadora de decisão ( WANDERLEY, 2009, p.189190 apud PLEIN, 2016, p.95) 
O processo de produção da agricultura familiar, nesse sentido, segue por dois caminhos. Um deles se refere ao consumo familiar ou para reincorporar ao processo produtivo. No segundo caminho, da troca, pode-se identificar que na as três formas de integração citadas por Polanyi.

Figura 02 - Dinâmica da Agricultura Familiar

Modos de organização social do processo econômico - chamadas de formas de integração Produção na agricultura familiar

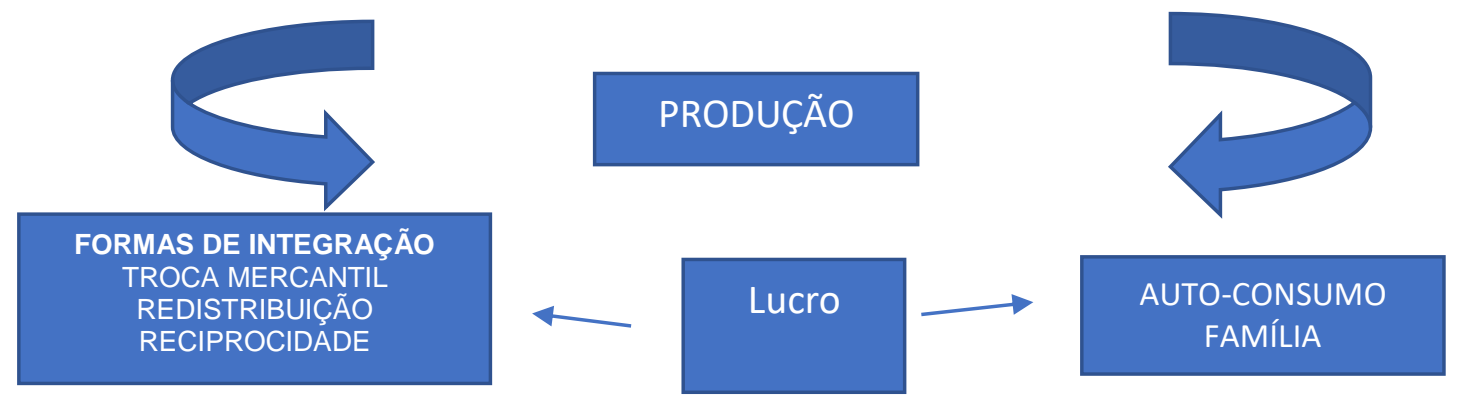

Fonte: Plein (2016), adaptado pelos autores.

Entre estudos e pesquisas que tem utilizado da obra de Karl Polanyi, Silva, et al (2011) estudando uma associação no município de Currais Novos/RN, concluíram que "podem ser encontrados formas de organização social fundamentadas nos princípios levantados por Karl Polanyi, dentro de uma realidade de Economia Solidária", mesmo sendo difícil de visualizar dentro da realidade econômica do século XXI, no "Povoado Cruz, é visível que, mesmo dentro de um contexto de economia de mercado, estes princípios são vivenciados" (SILVA, et al, 2011, p. 105 e 104).

Santos (2004, p. 12) consegue identificar na atual "Economia Solidária" princípios estabelecidos pela obra de Polanyi: "Na 'economia solidária', o princípio da reciprocidade aparece ao lado do mercado e da redistribuição, adquirindo o papel que tinha antes de ter sido ofuscado pelos outros dois princípios".

RADOMKSY e SCHNEIDER (2007) afirmam que a reciprocidade tem, ainda hoje, a capacidade de reforçar as relações sociais ao unir os membros de um grupo por meio de suas condutas, isto é, “das obrigações morais e da liberdade do agir recíproco e da carga simbólica que contém o dar e o retribuir” (RADOMSKY e SCHNEIDER, 2007, p. 255).

Outro aspecto que caracteriza a agricultura familiar é a fusão das três esferas (econômica, territorial e social), conforme apontado na figura 01, em organização produtiva, onde as atividades econômicas integram-se a valores sociais, à identidade cultural e a laços comunitários para garantir a reprodução social (AMBROSINI; FILIPPI, 2008). É o conceito de 
embeddedness $^{6}$, de enraizamento, já que mesmo o mercado se instalando, elementos sociais ainda permanecem.

Essas características da agricultura familiar: diversidade, produção baseada nas diferentes formas de integração, modo de produção tradicional, é uma resposta dos agricultores ao modelo dominante de oferta de tecnologia. Atualmente, para a construção de um desenvolvimento rural sustentável há a necessidade de "novos modelos de comportamento produtivo e relações que estejam enraizadas em contextos sociais, ambientais e políticos” (MARSDEN, 2003, p.250).

Assim, fazer o desenvolvimento rural é o devir de um projeto político, a ser instituído através da ação deliberada dos atores sociais e das organizações envolvidas, bem como de toda a sociedade (SCHNEIDER e ESCHER, 2011).

E nessa perspectiva, Polanyi (2012) acredita que o problema da indústria (mercado) se resolve pela ação planejada do Estado dos próprios produtores e consumidores. No caso do Estado, Polanyi (2012) entende que compete ao mesmo proteger a sociedade contra os desequilíbrios estruturais, assegurar boas condições de vida, desempenhando um papel de agente distribuidor e organizador de forma proativa, se antecipando as demandas sociais. "O poder existe para ser exercido em prol de garantir a permanência social e a regulação social, sendo que a opinião individual das pessoas é importante e deve ser levado em conta para exercer tal poder" (POLANYI, 2000, p. 299).

Em relação as políticas públicas e a atuação do Estado, Schneider e Escher (2011) apontam para a construção de processos politicamente orientados, buscando a criação de padrões de troca e distribuição mais autônomos, constituídos sobre relações de reciprocidade, de troca socialmente regulada e de redistribuição, através do movimento de bens e serviços em direção a centros determinados, e de seu retorno aos consumidores por meio de mecanismos institucionalizados em dispositivos coletivos e públicos, articulados entre instâncias do estado e da sociedade civil. Como exemplo de política pública nesse sentido, pode-se citar o PNAE (Programa Nacional de Alimentação Escolar), que prevê que no mínimo 30\% dos recursos federais para a alimentação escolar sejam destinados a aquisição desses alimentos é que a agricultura familiar passou a ser ator nas políticas públicas (GRISA e SCHNEIDER, 2015).

Escher (2011), também afirma que os agricultores familiares "se veem na necessidade de reorientar as suas formas de atuação em termos mais propositivos e proativos", no plano institucional, inclusive, "ocupando postos em instâncias do Estado e colaborando com a formulação de políticas públicas", constituindo assim, conforme o autor, "como uma série de

\footnotetext{
${ }^{6} \mathrm{O}$ conceito se refere à formação de significado para as ações dos atores inseridos num contexto ou ambiente institucional historicamente determinado, e expressa a ideia de que as estruturas sociais, estabelecidas e enraizadas em regras, normas, convenções, hábitos, etc. condicionam o comportamento social dos indivíduos (SCHNEIDER e ESCHER, 2011).
} 
'contramovimentos' da agricultura familiar" (ESCHER, 2011, p. 139), o que vem de encontro com a ideia de contramovimento de Polanyi.

Nesse processo, quando confrontados com os mercados, os agricultores podem criar espaços de manobra, buscando aumentar a agregação de valor ou os ganhos substantivos, dentro de uma dinâmica territorial ligada ao dinamismo do meio rural. Como exemplo, pode-se citar as cadeias alimentares curtas, agroindústrias familiares, redes de associação e cooperação (comércio justo, certificação solidária, redes de cooperativas locais). (SCHNEIDER e ESCHER, 2011).

Para Polanyi (2012), é importante a regulação social sobre a economia e as instituições como instâncias mediadoras entre as estruturas socioeconômicas e os indivíduos (atores sociais).

Pode-se inferir a partir dos conceitos constantes na obra de Karl Polanyi que o desenvolvimento rural precisa ser construído através da ação coletiva, expressa por meio da política, mas que isso só acontecerá se houver uma visão do homem e da sociedade diferente daquela herdada na economia de mercado (POLANYI, 2012).

\section{Considerações Finais}

Ao revisitar este autor que escreveu sua obra na primeira metade do século XX, pode-se identificar sua atualidade para compreender os processos de desenvolvimento ou, mais especificamente, de desenvolvimento rural centrado na agricultura familiar. Suas reflexões são atemporais. O autor consegue, ao mesmo tempo, perceber as modificações na "autonomia relativa" dos agricultores à medida que o capitalismo entra na agricultura, bem como, identifica as alternativas destes mesmos agricultores frente aos novos desafios. Se, por um lado, as relações capitalistas criam um ambiente extremamente hostil para os agricultores, por outro lado, estes reagem ao processo, construindo alternativas na busca por um certo grau de autonomia.

As leituras e o entendimento a respeito da obra de Polanyi sobre a agricultura familiar, como exposto nesse artigo, demonstra que o autor ainda precisa ser estudado, indo além da incipiente análise que este artigo propõe.

\section{Referências}

ABRAMOVAY, R. Entre deus e o diabo: mercados $e$ interação humana nas ciências sociais. Tempo Social, v. 16, n. 2, p. 35-64, 2004.

Uma nova extensão rural para a agricultura familiar. In: SEMINÁRIO NACIONAL DE ASSISTÊNCIA TÉCNICA E EXTENSÃ̃ RURAL, 1., 1997, Brasília. Anais... Brasília: PNUD, 1997.

. Paradigmas do capitalismo agrário em questão. 3. ed. São Paulo: Edusp, 2012. 
ALMEIDA, J. Da ideologia do progresso à ideia de desenvolvimento (rural) sustentável. 2015. Disponível em: http://cursos.unipampa.edu.br/cursos/lecampodp/files/2016/01/Desenvolvimento-Rural-Sustent\%C3\%A1vel-jalcione.pdf Acesso em 21 jun 2018.

AMBROSINI, L. B., \& FILIPPI, E. E. Da era do desenvolvimento ao desenvolvimento rural: sistemas produtivos localizados sob a perspectiva de Karl Polanyi. REDES, 2008, 13(3), 121139.

BREITENBACH, R. FROEHLICH, J.M. BRANDÃO, J.B. Estratégia Emergencial Reativa de Desenvolvimento Local: Mobilização $\quad$ Social para Intensificação da Produção Leiteira. Revista Desenvolvimento em Questão. Editora Unijuí, ano 7.n. 13 jan./jun. 2009.

DOPFER, K. Development theory. In: HODGSON, G.M. SAMUELS, W.J. TOOL, M.R (ed.) The elgar companion to institutional and evolutionary economics. New York: Edward Elgar, 1994. P.145-152.

ELLIS, F.; BIGGS, S. Evolving Themes in Rural Development 1950s-2000s Development Policy Review 19 (4), 437-448. Blackwell Publishing Ltda, 2001. Disponível em: http://www.blackwell-synergy.com/toc/dpr/19/4 \#. Acesso em 01 jul 2018.

ESCHER, Fabiano. Os assaltos do moinho satânico nos campos e os contramovimentos da agricultura familiar: atores sociais, instituições e desenvolvimento rural no Sudoeste do Paraná. 2011. Dissertação (Mestrado). Programa de Pós-Graduação em Desenvolvimento Rural, Universidade Federal do Rio Grande do Sul, Porto Alegre, 2011.

FAO "Agricultura familiar: evolución conceptual, desafios y institucionalidad en América Latina y el Caribe", II Foro del Frente Parlamentario Contra el Hambre, 7 y 8 de junio, Bogotá (Colombia), 2011.

GIL, A.C. Métodos e Técnicas de Pesquisa Social. São Paulo: Editora Atlas, 1994.

GRISA, C. SCHNEIDER, S. Políticas públicas de desenvolvimento rural no Brasil / Organizadores Catia Grisa [e] Sergio Schneider. - Porto Alegre: Editora da UFRGS, 2015. 624 p.

LISBOA, A. de M. A atualidade de Karl Polanyi para a reconstrução do pensamento econômico. Otra Economía, v. 2, n. 3, 2, p. 7-26, 2008.

MARSDEN, T. The condition of rural sustainability. Assen (Netherlands): Van Gorcun, 2003.

PEREIRA, A.C.F.D.; Polanyi e a economia social e solidária: contributos para respostas aos problemas sociais atuais. Dissertação (Mestrado em Economia Social e Solidária). ISCTE IUL, Instituto Universitário de Lisboa, 2016, 93 p.

POLANYI, K. A grande transformação. 2. ed. Rio de Janeiro: Elsevier, 2000.

A subsistência do homem e ensaios correlatos. Tradução Vera Ribeiro. Rio de Janeiro: Contraponto, 2012.

PLEIN, C. Desenvolvimento, mercados e agricultura familiar: uma abordagem institucional da pobreza rural. Curitiba, PR. CRV, 2016.

PLOEG, J. D. V.D et al. Rural development: from practices and policies towards theory. Sociologia Ruralis, Oxford, UK, v. 40, n. 4, p. 391-408, out. 2000.

. Dez qualidades da agricultura familiar. Cadernos de Debate. Revista Agriculturas: experiências em agroecologia, AS-PTA Agricultura Familiar e Agroecologia integrado à Agricultures Network No 01, fevereiro de 2014. 
RADOMSKY, G. F. W., \& SCHNEIDER, S. Nas teias da economia: o papel das redes sociais e da reciprocidade nos processos locais de desenvolvimento. Sociedade e Estado. 22(2),2007 249284.

RICHARDSON, R. J. Pesquisa social: métodos e técnicas. 3. ed. São Paulo: Atlas, 1999.

RODRIGUES, W. SANTOS, N.S. Karl Polanyi e o desenvolvimento econômico: um novo olhar sobre o regional/local? Revista de Desenvolvimento Econômico - RDE Salvador, BA - Ano XIX - V. 1 - N. 36. - P. 168 - 190, 2017.

SANTOS, A. B. Necessidade de uma economia solidária: a visão de Karl Polanyi sobre os mercados. Ideas, p. 1-14, 2004.

SCHNEIDER, S. A presença e as potencialidades da agricultura familiar na América Latina e no Caribe. Redes (St. Cruz Sul, Online), v. 21, no 3, p. 11 - 33, set./dez. 2016.

SCHNEIDER, S.; SILVA, M.K.; MARQUES, P. E. M. (Org.) Políticas Públicas e Participação Social no Brasil Rural. 2ed. Porto Alegre: Editora da UFRGS, 2009. (Série Estudos Rurais)

SCHNEIDER, S. ESCHER, F. A contribuição de Karl Polanyi para a sociologia do desenvolvimento rural. Sociologias, Porto Alegre, ano 13, n.27, mai/ago.2011, p.180-219.

SILVA, F. A. G., CALAZANS, D.L.M e S; GONZALEZ, J.M.R; SOUZA, W.J. Os princípios de economia substantiva de Karl Polanyi em relações de economia solidária: o caso do povoado de Cruz (Currais Novos/RN). RECADM, Campo Largo, v. 10, n. 2, jul./dez., 2011, p. 93-106.

STIGLITZ. J. Prefácio.: In Polanyi, K. (Ed.). A Grande Transformação: as origens políticas e económicas do nosso tempo. Lisboa: Edições 70. 2012. p. 9-37.

TINOCO, S.T.J. Análise socioeconômica da piscicultura em unidades de produção agropecuária familiares da região de Tupã, SP. 2006. 69 p. Tese. UNESP, São Paulo,2006.

WANDERLEY, M. N. B. A emergência de uma nova ruralidade nas sociedades modernas avançadas - o "rural" como espaço singular e ator coletivo. Estudos Sociedade e Agricultura, n. 15 , p. 87-145, 2001.

. O mundo rural como um espaço de vida: reflexões sobre a propriedade da terra, agricultura familiar e ruralidade. Porto Alegre: Editora da UFRGS, 2009. 